năm điều trị thứ hai so với thứ nhất. Điều đó cho thây ý nghĩa của chương trình QLHNT trong việc giảm thiểu $\mathrm{CP}$ điều trị cho người bênh xét ở cả $\mathrm{CP}$ trực tiếp y tế hay ở $\mathrm{CP}$ tiền túi của người bệnh ( $C P$ TT NYT và $C P \mathrm{GT}$ ). Điều này có thể được giải thích bởi chương trình QLHNT giúp nâng cao hiệu quả điều trị, giảm thiểu số đợt nhập viện nội trú và giảm thiểu diễn tiến nặng hơn của bênh.

Ngoài ra, nghiên cứu ghi nhận CP TTYT trong điều trị HPQ chiếm tỷ lệ cao nhất với 67,41 $73,84 \%$ tổng $\mathrm{CP}$ điều trị. Kết quả này tương đồng với nghiên cứu của Miriam năm 2003 tai Mỹ, trong đó $\mathrm{CP}$ bình quân hàng năm cho mỗi NB HPQ gồm $65 \% \mathrm{CP}$ trực tiếp và $35 \% \mathrm{CP}$ GT [8]. Như vậy, có thể thấy CP TT YT là gánh nặng kinh tế lớn trong điều trị $\mathrm{HPQ}$, vì vậy việc giảm thiểu gánh nặng kinh tế của bệnh cần cẩn nhắc giảm thiểu các cấu phần CP TTYT.

Đây là nghiên cứu đầu tiên tại bệnh viện quận 11 đánh giá lợi ích của chương trình QLHNT trong điều trị HPQ ở khía cạnh CP điều trị. Nghiên cứu đã đánh giá toàn diện $\mathrm{CP}$ điều trị $\mathrm{HPQ}$ theo quan điểm của người chi trả và theo dõi quần thể NB HPQ tham gia chương trình QLHPQ trong hai năm liên tục. Tuy nhiên nghiên cứu còn tồn tại một số hạn chế. Với tình hình dịch bệnh COVID-19 ảnh hưởng đến tình hình khám chữa bệnh nói chung và tại bệnh viện quận 11 nói riêng trong năm 2020, nghiên cứu đã không bao gồm dữ liệu NB HPQ năm 2020. Ngoài ra, nghiên cứu mới chỉ dừng lại ở việc khảo sát $\mathrm{CP}$ điều trị $\mathrm{HPQ}$ qua 2 năm NB tham gia chương trình QLHNT và chưa đánh giá được toàn diện tính chi phí - hiệu quả của chương trình QLHNT.

\section{KẾT LUÂN}

Chương trình quản lý hen ngoai trú tại bênh viện Quận 11 giúp giảm tổng $C P$ điều trị của người bệnh $\mathrm{HPQ}$ sau 2 năm tham gia điều trị. Cân tiếp tục triển khai chương trình và đánh giá tính chi phí - hiệu quả của chương trình trên nhiều quan điểm khác nhau trong tương lai.

\section{TÀI LIẸU THAM KHẢO}

1. https://www.who.int/vietnam/vi/news/featu re-stories/detail/ten-threats-to-global-health-in2019 truy cập 01/10/2021

2. Global initiative for asthma (GINA) (2015) Definitison, description and diagnosis of asthma, Global strategy for asthma management and prevention.

3. Sauni Riitta, Panu Oksa (2003), Increased risk of asthma among Finnish construction workers, Occupational Medecine 53(8), 527-531.

4. S.K. Chhabra (2007), Assessment of Control in Asthma: Current Scenario and Instruments for Measurement, Indian J Chest Dis Allied Sci 2007; 49: 5-7

5. Võ Thi Rĩ, Pham Anh Tuấn (2018), Tình hình bệnh tật và hiệu quả quản lý bệnh nhân hen/ COPD đến khám tại phòng khám hổ hấp bệnh viện Quận 11, Hội nghị Khoa học kỹ thuật lần I - Bệnh viện Quận 11, trang 45 - 50.

6. Nguyến Thanh Bình (2020), Dịch tễ dược học, Nhà xữát bản $Y$ học.

7. Nguyễn Thi Thu Thủy (2020), Kinh tế dược trong thực hành lâm sàng, nhà xuất bản Đại học quốc gia Tp. Hồ Chí Minh.

8. Cisternas MG, Blanc PD, Yen IH, Katz PP Earnest G, Eisner MD, Shiboski S, Yelin EH. A comprehensive study of the direct and indirect costs of adult asthma. J Allergy Clin Immunol. 2003 Jun;111(6):1212-8.

\title{
KẾT QUẢ SớM PHẪU THUÂTT KHÂU THÌ ĐẦU ĐIỀU TRI THỦNG THỰC QUẢN
}

Lý Minh Tùng*, Lê Quang Nghĩa*, Trần Văn Minh Tuấn*, Trần Hữu Duy*

\section{TÓM TẮT}

Đắt vấn đê: Thủng thực quản là một cấp cứu ngoại khoa hiếm gặp có tỉ lệ biến chứng và tử vong cao. Lựa chọn phương pháp điều trị tốt nhất cho bệnh nhân còn nhiều tranh luân. Hiên nay, khâu thì đâu dần được xem là một phương pháp điêu trị hợp lý do tỉ lệ

*Đai hoc Quốc Gia TP. Hồ Chí Minh

Chịu trách nhiệm chính: Lý Minh Tùng

Email: Imtung@medvnu.edu.vn

Ngày nhận bài: 7.9.2021

Ngày phản biên khoa hoc: 28.10.2021

Ngày duyệt bài: 10.11.2021 thành công cao, ngay cả trong những trường hợp thủng thực quản đến trễ. Nghiên cứu này nhằm đánh giá kết quả sớm của điều trị khâu thì đầu trong thủng thực quản trong 5 năm gần đây tai bênh viện Bình Dân. Phương pháp nghiên cứu: Mô tả hàng loạt ca thủng thươ quản được điều trị khâu thức quản thì đầu tại bệnh viện Bình Dân trong khoảng thời gian 5 năm từ 2015 đển 2020. Kết quả: Có 24 bệnh nhân được khâu thực quản thì đầu, gôm 10 ca thủng thực quản ở cổ (42\%), 10 ca ở ngực (42\%) và 4 ca ở bụng (16\%). Khâu thì đâu có tỉ lệ thành công chung là $88 \%$. Tỉ lệ rò miệng khâu là 8 ca (33\%), trong đó phải mổ lại 3 ca $(12 \%)$. Không có ca nào tử vong. Kết luận: Chẩn đoán thủng thực quản còn nhiều thách thức, cần chẩn 
đoán sớm để giảm tỉ lệ tử vong. Khâu thì đâu là một lựa chọn tốt cho thủng thực quản, có tỉ lệ thành công cao.

Tứ khóa: khâu thì đầu, thưng thực quản.

\section{SUMMARY}

SHORT-TERM OUTCOME OF PRIMARY REPAIR FOR ESOPHAGEAL PERFORATION

Introduction: Esophageal perforations are rare injuries but associated with a high rate of morbidity and mortality. However, the optimal cure for individual is still a controversy. There is an increasing consensus that primary repair provides good results for esophageal perforations, even not diagnosed on time. Therefore, we review and describe short-term outcomes of primary repair for esophageal perforation at the Binh Dan hospital in a 5 years period. Materials and Methods: A case-series study was conducted to describe the outcomes of primary repair for esophageal perforation at the Binh Dan hospital in a 5 years period from 2015 through 2020. Results: Primary repair for thoracic esophageal perforations was applied in 24 out of 38 consecutive patients. Regarding esophageal location, 10 (42\%) patients presented cervical, $10(42 \%)$ thoracic, and $4(16 \%)$ abdominal injuries. Overall successful rate was $88 \%, 3$ patients $(12 \%)$ need a second operation. Leakage occurred after primary repair in $8(33 \%)$ patients. No mortality was reported. Conclusion: The diagnosis and management of esophageal perforation remains a challenging clinical problem. Primary repair is the treatment of choice for esophageal perforation with highly successful rate.

Key word: esophageal perforation, primary repair

\section{I. ĐặT VẤN ĐỀ}

Thủng thực quản (TQ) là một cấp cứu ngoại khoa hiếm gặp nhưng có tỉ lệ biến chứng và tử vong cao. Lựa chọn phương pháp điều trị tốt nhất cho bệnh nhẩn (BN) vần còn nhiều tranh luận và thách thức. Yếu tố chính giúp tiên lượng trong thủng thực quản là thời gian phát hiện. Tỉ lệ tử vong sẽ tăng lên gấp 2 lần nếu điều trị chậm hơn 24 tiếng sau khi thủng. Phẫu thuật khẩu lại thì đầu kèm dẫn lưu rộng rãi trung thất được xem là lựa chọn điều trị thích hợp cho thủng thực quản phát hiện sớm. Hiện nay, ngày càng có nhiêu nghiên cứu cho thấy áp dụng khâu thì đầu trong những trường hợp thủng thực quản đến muộn cũng cho kết quả khả quan ${ }^{(7)}$.

Tại Việt Nam, nguyên nhân hàng đầu gây thủng thực quản là do dị vật và TQ ngực là vị trí tổn thương nhiều nhất( $(3,4)$. Phương pháp điều trị tốt nhất không có khuôn mẫu chung mà cần cá thể hóa tùy vào đặc điểm lâm sàng của từng bệnh nhân. Tại bệnh viện Bình Dân, tùy theo đặc điểm tổn thương và tình trạng bệnh nhân, chúng tôi sử dụng nhiều phương án điều trị khác nhau. Trong đó, khâu thì đầu được chúng tôi thực hiện trong phần lớn các trường hợp và có tỉ lệ thành công cao. Chúng tôi thực hiện nghiên cứu này nhằm mục đích đánh giá lại kết quả sớm của khâu thì đầu điều trị thủng thực quản trong 5 năm từ 2015 đến 2020.

\section{II. ĐỐI TƯƠNG VÀ PHƯƠNG PHÁP NGHIÊN CỨU}

Đối tượng nghiên cứu: những $B N$ nhập viện được chẩn đoán thủng $T Q$ và được điều trị bằng khâu thì đầu tại bệnh viện Bình Dân trong khoảng thời gian 5 năm từ 2015 đến 2020 .

Thiết kế nghiên cứu: hồi cứu, báo cáo hàng loạt ca

\section{KẾT QUẢ NGHIÊN CỨU}

Tại bệnh viện Bình Dân, trong khoảng thời gian 5 nămm, chúng tôi ghi nhận có 24 ca được phẫu thuật khâu thì đầu trong số $38 \mathrm{ca}$ thủng thực quản nhập viện, chiếm $63 \%$. Trong đó có 9 BN nữ và 15 BN nam. Tuổi trung bình là 44 tuổi. Nguyên nhân gây thủng TQ ở nghiên cứu này gồm do dị vật đường tiêu hóa chiếm $42 \%$, do tai biến nội soi $42 \%$, do tai biến phẫu thuât $4 \%$, do hội chứng Boerhaave $14 \%$. Về vị trí tổn thương, có 10 ca tổn thương thực quản cổ $(42 \%), 10 \mathrm{ca}$ tổn thương thực quản ngực (42\%) và 4 ca tổn thương thực quản bụng (16\%).

Bảng tóm tắt kêt quả điều trị giữa 2 nhóm phát hiện sớm và muộn.

\begin{tabular}{|c|c|c|c|c|c|c|}
\hline \multirow{2}{*}{$\begin{array}{l}\text { Thời gian nằm viện trung bình (ngày) } \\
\text { Rò miệng khâu: }\end{array}$} & \multicolumn{2}{|c|}{$\begin{array}{c}\text { Phát hiện sớm } \\
(n=18)\end{array}$} & \multicolumn{2}{|c|}{$\begin{array}{c}\text { Phát hiện muộn } \\
(n=6)\end{array}$} & \multicolumn{2}{|c|}{$\begin{array}{l}\text { Chung } \\
(n=24)\end{array}$} \\
\hline & & & & 6,7 & & 9,4 \\
\hline $\begin{array}{c}\text { Rò miềng khâu: } \\
-C \hat{O} \\
-N g u ̛ c \\
-B u ̛ ̣ g \\
\end{array}$ & $\begin{array}{l}3 \\
1 \\
2 \\
0\end{array}$ & $17 \%$ & $\begin{array}{l}5 \\
2 \\
3 \\
0\end{array}$ & $83 \%$ & 8 & $33 \%$ \\
\hline $\begin{array}{l}\text { Mố lại } \\
\text { - Cổ } \\
\text { - Ngức } \\
\text { - Bụng }\end{array}$ & $\begin{array}{l}1 \\
0 \\
1 \\
0\end{array}$ & $6 \%$ & $\begin{array}{l}2 \\
1 \\
1 \\
0\end{array}$ & $33 \%$ & $\begin{array}{l}2 \\
0\end{array}$ & $12,5 \%$ \\
\hline Rò TQ & 1 & $6 \%$ & 1 & $17 \%$ & 2 & $8 \%$ \\
\hline Tứ vong & 0 & & 0 & & 0 & \\
\hline
\end{tabular}


Có 18 (75\%) BN chẩn đoán sớm (trước 24 tiếng) và $6(25 \%)$ BN chẩn đoán muộn. Tỉ lệ được chẩn đoán sớm cao ở thủng TQ cổ và̀ thủng TQ ngực (trên $80 \%$ ). Tỉ lệ chẩn đoán muộn ở thủng TQ bụng là $75 \%$.

Trong 24 ca phẫu thuật có 20 ca mổ mở và 4 ca phẫu thuật nội soi. Có 3 ca nội soi lồng ngực và $1 \mathrm{ca}$ nội soi ổ bung. Tất cả trường hợp phẩu thuật nội soi đều thành công.

Thời gian nằm viện trung bình là $22 \pm 9,4$ ngày (10-40 ngày), nhóm chẩn đoán sớm là 20,5 $\pm 9,6$ ngày và nhóm chẩn đoán muộn là $28 \pm$ 6,7 ngày.

Tỉ lệ thành công là $88 \%$. Có 3 ca (12\%) phải mổ lại gồm 2 ca thủng TQ ngực và 1 ca thủng TQ cổ, phải mổ chuyển lưu cô lập TQ sau đó. Tỉ lệ rò miệng khâu là $33 \%$, điều trị nội khoa thành công $3 \mathrm{ca}$, diễn tiến rò thực quản 2 ca và mổ lại $3 \mathrm{ca}$. Không có trường hợp tử vong.

Sự khác biệt về thời gian trung bình nằm viện, tỉ lệ biến chứng giữa 2 nhóm được chẩn đoán sớm và muộn không có ý nghĩa thống kê.

\section{BÀN LUÂN}

Thủng TQ là một bệnh cảnh hiếm gặp, có tỉ lệ tử vong cao, đặc biệt khi bệnh nhân nhập viện muộn sau 24 giờ. Về tuổi và giới tính, nghiển cứu của chúng tôi có số liệu khác so với một số tác giả trên thế giới nhưng tương đồng với các số liệu của các nghiên cứu ở Việt Nam ${ }^{(3,4,12)}$. Tuổi trung bình mắc tại Việt Nam tương đối trẻ hơn so với các nghiên cứu trên thế giới. Nguyên nhân hàng đâu gây thủng TQ theo các nghiên cứu trên thế giới là do tai biến can thiệp y khoa, chiếm hơn $50 \%(6,7,9)$. Tại Việt Nam, dị vật tiêu hóa là nguyên nhân hàng đâu gây thủng $T Q$, đặc biệt là mảnh xương(12). Nghiên cứu của chúng tôi cũng có số liệu tương tự với nguyên nhân do dị vật tiêu hóa chiếm $42 \%$.

Sau khi võ, do áp lực âm của khoang màng phổi và mô liên kết lỏng lẻo quanh thực quản, dịch tiêu hóa sẽ lan vào trung thất. Nhiểm trùng sẽ lan rộng gây viêm nhiễm các cơ quan ở trung thất và cạnh trung thất, từ đó gây nhiễm trùng huyết và suy đa cơ quan, dẫn đến tử vong. Với bệnh cảnh thủng thực quản, chỉ một số ít $\mathrm{BN}$ đáp ứng các tiêu chí như tổn thương nhỏ, dây nhiễm xung quanh ít, không có dấu hiệu nhiễm trùng và không có bệnh lý của $T Q$ trước đó có thể điều trị bảo tồn ${ }^{(11)}$. Tất cả BN khác cần được phẫu thuật càng sớm càng tốt. Nguyên tắc phẩu thuật bao gồm: bộc lộ rộng rãi, loại bỏ mô hoại tử, làm kín tổn thương, dẩn lưu tối đa(7). Năm 1947, Barrett lần đâuu báo cáo 1 ca khâu thì đầu điều trị thủng thực quản thành công. Cho đến nay, khâu thì đầu vẫn được xem là phương pháp phấu thuật thích hợp cho những tổn thương phát hiện sớm. Với những tổn thương phát hiện muộn, ngày càng có nhiều nghiên cứu cho thấy khâu thì đầu cũng là một lựa chọn thích hợp. Theo Wright, nguyên nhân gẩy tử vong ở những trường hợp đến muộn không phải do khâu thất bại mà liển quan đến những vấn đề nhiễm trùng nhiễm độc có trước khi điều trị̣(6). Nghiên cứu của Sung cũng đưa ra luận điểm tương tự khi nhân thấy mặc dù lỗ thủng đã được khâu kín, nhiễm trùng và suy đa cơ quan vẫn tiếp tục phát triển vào ngày thứ hai hậu phẫu và là nguyên nhân chính gây tử vong. Do đó, cùng với sự tiến bộ của phương tiện và kỹ thuật hồi sức, ngày càng có nhiều nghiên cứu cho thấy khâu thì đâu trong những trường hợp đến muộn có tỉ lệ thành

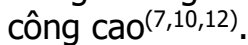

Với tổn thương thủng TQ cổ, khâu thì đầu là lựa chọn đầu tiên. Đường mố dọc cơ ức đòn chũm ở cổ $(T)$ nếu tổn thương khu trú hoăc ngang cổ nếu tổn thương lan rộng 2 bên. Tổn thương ở cổ có thể khâu một lớp hoặc 2 lớp, khi cần có thể tăng cường bởi một phần cơ ức đòn chũm hoặc cơ nhị thân. Vì tổn thương $T Q$ cổ thường khu trú, ít lan rộng và dễ lành hơn nên không cần thiết phải bộc lộ hoàn toàn 2 đầu tân ở lớp niêm của tổn thương. Dẫn lưu rộng rãi cần áp dụng trong tất cả các trường hợp, cos thể dẫn lưu đến trung thất trên và để hở da nếu cần $(1,7)$. Trong nghiên cứu của chúng tôi, không có ca nào chúng tôi khâu tăng cường bằng vạt cơ lân cận và tî lệ thành công là $90 \%$. Có một trường hợp thất bại phải mở $\mathrm{TQ}$ cổ ra da do vết thủng chiếm gần $1 \frac{1}{2}$ chu vi và rò nhiều sau phẫu thuật. Một số nghiên cứu khuyên nên mở dạ dày ra da để nuôi ăn sớm. Tuy nhiên, Tất cả BN thủng TQ cổ khâu thì đầu trong nghiên cứu của chúng tôi đều không cần mở dạ dày ra da, chỉ cần đặt thông mũi - dạ dày để nuôi ăn sớm cho BN. Với thủng TQ ngực đến sớm, khâu thì đâu là lựa chọn tốt nhất $(6,13)$. Về đường mổ, ưu tiên chọn vào khoang màng phổi nào có tổn thương săn để hạn chế việc tổn thương lan vào khoang còn lại. Nếu chưa có tổn thương khoang màng phổi trước đó, đường vào ngực là liên sườn V bên phải khi tổn thương ở $1 / 3$ trên hoặc $1 / 3$ giữa $\mathrm{TQ}$ và liên sườn VII bên trái hoặc đường giữa bụng trên rốn khi tổn thương ở $1 / 3$ dưới $\mathrm{TQ}^{(1)}$. Khác với $\mathrm{TQ}$ cổ, lỗ thủng ở TQ ngực cần được bộc lộ hoàn toàn đến lớp niêm. Tổn thương ở lởp niêm thường dài hơn so với tổn thương nhìn thấy ở lớp cơ, do đó cần mở rộng dọc theo lớp cơ để 
bộc lộ rõ 2 đầu tận của lớp niêm trước khi tiến hành khâu. Theo Blasberg và Wright, lỗ thủng sau khi khâu nên được tăng cường bởi một vạt cơ giàu máu nuôi boc lấy tổn thương. Việc khâuu tăng cường cần thiết ngay cả khi tổn thương sạch vì giúp ổn định vết khâu tốt hơn ${ }^{(6)}$. Trong nghiên cứu của chúng tôi, chúng tôi thực hiện 7 ca khâu 2 lớp đơn thuần và 3 ca khâu tăng cường bằng vạt cơ liên sườn. Tỉ lệ thành công là $80 \%$. Cả 2 nhóm đều có một ca phải phẫu thuật laai. Nhìn chung, những ca được khâu tăng cường là những ca nặng đến trễ, mô thực quản thủng dài hơn $2 \mathrm{~cm}$ và nhiều mô hoại tử. Sau khi khâu, chúng tôi đặt các ống dẫn lưu lớn ở khoang màng phổi và cạnh lỗ thủng để giúp dẫn lưu dịch và mô nhiếm trùng còn lại, đồng thời dẫn lưu dịch tiêu hóa nếu vết khâu bị rò. Sau 7 ngày, chúng tôi chụp TQ cản quang kiểm tra và rút dẫn lưu nếu tổn thương lành và lưu thông $T Q$ tốt. Chirica khuyên nên mở da dày ra da hoặc mở hỗng tràng nuôi ăn kết hợp với ống thông mũi - dạ dày nhằm giải áp, chống trào ngược dịch da dày và có thể cho $B N$ ăn sớm(7). Theo Vũ Hữu vĩnh, việc mở da dày nuôi ăn không cần thiết khi có 56/64 trường hợp không có mở dạ dày vẫn có kết quả tốt(12). Với thủng TQ bụng, Biancari khuyến cáo mở bụng dùng đường giữa trên rốn để tiếp cận tổn thương hơn là mở ngực ${ }^{(5)}$. Dùng đáy vị hoặc cơ hoành để khâu tăng cường nếu cần. Đặt thông dạ dày và mở dạ dày hoặc hống tràng nuôi ăn là cần thiết (7). Vể phâuu thuật ít xâm lấn, phẫu thuật nội soi có thể được áp dụng nếu tình trạng $B N$ cho phép và kỹ năng của phẩu thuật viên tốt ${ }^{(9)}$. Chúng tôi thực hiện 1 trường hợp nội soi bụng và 3 trường hợp nội soi lồng ngực. Đây là những trường hợp lỗ thủng nhỏ phát hiện sớm và nhiếm trùng không lan rộng. Những ca thủng $\mathrm{TQ}$ ngực này xét về chỉ định có thể điêu trị bằng nội soi tiêu hóa với Over-the-scope clip(2), nhưng chúng tôi không có loại dụng cụ này nên chọn phương án ít xâm lấn thay thế là mổ nội soi. Tất cả các trường hợp này đều thành công.

Tỉ lệ rò miệng khâu sau phẫu thuật khâu thì đầu được báo cáo khoảng 40-50\%, trong số đó diễn tiến thành rò thực quản ra da khoảng $38 \%$. không ủng hộ việc khâu tăng cường bằng mảnh vạt tự thân. Theo Whyte, tỉ lệ rò khi khâu tăng cường không khác biệt so với khâu đơn thuần. Nghiên cứu nhấn mạnh kỹ thuật khâu tỉ mỉ là yếu tố chính giúp lỗ thủng kín và̀ không gây hẹp thực quản. Tuy nhiên, phần lớn các nghiên cứu hiện nay đều đồng ý nên dùng vạt cân cơ để khâu tăng cường ${ }^{(5,7,10)}$. Wright cho rằng vạt tăng cường giúp rò vết khâu nếu xảy ra sẽ tự giới hạn và có thể điều trị bảo tồn. Chúng tôi có 3 ca thủng TQ ngực sử dụng vạt khâu tăng cường. Tỉ lệ rò miệng khâu sau mổ của chúng tôi là 33\% (8 ca). Có 2 trong 3 ca khâu tăng cường bị rò miệng khâu: 1 ca tự lành và 1 ca phải phẫu thuật lại. Có 6 trong 21 ca khâu đơn thuần bị rò, gồm: 2 ca lành sau khi điều trị nội khoa (đều ớ cổ), 2 ca chuyển thành rò thực quản ra da ( 1 ở cố, 1 ở ngực) và 2 ca phải phẩu thuật lại (1 ở cổ, 1 ở ngực).

Theo nghiên cứu của Sung, khâu thì đầu có kết quả tốt với biến chứng và tỉ lệ tử vong thấp, ngay cả với những trường hợp đến muộn. Tỉ lệ tử vong chung là $5 \%(0 \%$ ở những trường hợp phát hiện sớm và $7 \%$ ở những trường hợp phát hiện muộn). Nghiên cứu của Sung cho thấy không có sự liên quan giữa việc thất bại khi khâu với tỉ lệ tử vong. Nghiên cứu của chúng tôi cũng ủng hộ nhận định trên, khi có 5 trong 6 trường hợp đển trễ có rò chỗ khâu, thậm chí có 2 phải phấu thuật lại nhưng không có tử vong. Những trường hợp đến trễ này được chúng tôi dẫn lưu rộng rãi và tưới rửa mối ngày nhằm lây mô hoại tử và tránh nhiễm trùng lan rộng. Tỉ lệ tử vong chung do thủng thực quản tại bệnh viện chúng tôi là $8 \%$. Tuy nhiển, trong số những $B N$ được xử trí khâu thì đầu trong nghiên cứu này, chúng tôi không ghi nhận trường hợp nào tử vong. Những ca phát hiện trễ có thời gian nằm viện dài hơn so với phát hiện sớm, nhưng không có ý nghĩa thống kê.

Mặc dù có tỉ lệ thành công cao, khâu thì đầu không phải là phương pháp tốt nhất trong tất cả các trường hợp. Với các trường hợp thực quản hẹp hay có bệnh lý trước thủng, chúng ta nên lựa chọn các phương án vừa giải quyết tổn thương thủng thực quản vừa giải quyết sinh lý bệnh của bệnh lý kèm theo ${ }^{(7,8)}$.

\section{KẾT LUÂ̂N}

Thủng thực quản là một bệnh cảnh hiếm gặp, có đặc điểm lâm sàng rất đa dạng và không đặc hiệu, diễn tiến phức tạp. Tại Việt Nam, nguyển nhân chiếm phần lớn vẫn là dị vật xương động vật. Điều trị phẫu thuật rất đa dạng, tùy theo vị trí tổn thương và thời gian phát hiện. Khâu thì đầu là một lựa chọn tốt cho thủng thực quản, có tỉ lệ thành công cao cả trong trường hợp đến sớm và đến muộn. Điều trị bằng các kỹ thuật ít xâm lấn có thể áp dụng trong số trường hợp chọn lọc kỹ. Chúng ta cần áp dụng, nghiên cứu, đánh giá việc phối hợp biện pháp không xâm lấn nhằm mang lại lợi ích tối ưu cho BN. 
Nghiên cứu này được tài trợ bởi Đại học Quốc gia Thành phố Hồ Chí Minh (ĐHQG-HCM) trong khuôn khổ Đề tài mã số C2020-44-08

\section{TÀI LIÊU THAM KHẢO}

1. Lê Quang Nghĩa (2012) "Thủng, bục miệng nối và do thực quản". Tạp chí Y học Thành phố Hố Chí Minh 16, tr. 2-4.

2. Lê Quang Nhân (2015) "Nội soi khâu kín lỗ thủng thưc quản bằng over-the-scope clip: môt ca lâm sàng". Tạp chí Y học Thành phố Hồ Chí Minh, 19 , tr. 39-42.

3. Nguyển Công Minh (2013) "Hội chứng Boerhaave hay Hội chứng vỡ thực quản do nôn ói manh tại bệnh viên Chợ Rấy và Bệnh viên cấp cứu Trưng Vương trong 14 năm (1999-2012)". Tạp chí Y hoc Thành phố Hồ Chí Minh, 17, tr. 44-52.

4. Vũ Hữu Vĩnh, Nguyển Viết Đăng Quang, Lê Việt Anh (2016) "Xử trí khâu thì đầu tổn thương thúng thực quản". Tạp chí Y - Dược học Quân sự, 8 , tr. $150-155$.

5. Biancari F., D'Andrea V., Paone R., Di Marco C., Savino G., Koivukangas V.và cộng sự (2013) "Current treatment and outcome of esophageal perforations in adults: systematic review and meta-analysis of 75 studies". World J Surg, 37 (5), tr. 1051-9.

6. Blasberg Justin D., Wright Cameron D. (2015) "Management of Esophageal Perforation". Adult
Chest Surgery. 2nd ed. McGraw-Hill,

7. Chirica Mircea, Kelly Michael D., Siboni Stefano Aiolfi Alberto, Riva Carlo Galdino, Asti Emanuelevà cộng sự (2019) "Esophageal emergencies: WSES guidelines". World Journal of Emergency Surgery, 14 (1), tr. 26.

8. Cooke David T., Lau Christine L. (2008) "Primary Repair of Esophageal Perforation". Operative Techniques in Thoracic and Cardiovascular Surgery, 13 (2), tr. 126-137.

9. Dickinson Karen Joanna, Blackmon Shanda H. (2015) "Endoscopic Techniques for the Management of Esophageal Perforation". Operative Techniques in Thoracic and Cardiovascular Surgery, 20 (3), tr. 251-278.

10. Fattahi Masoom S. H., Nouri Dalouee M. Fattahi A. S., Hajebi Khaniki S. (2018) "Surgical management of early and late esophageal perforation". Asian Cardiovasc Thorac Ann, 26 (9), tr. 685-689.

11. Hasimoto C. N., Cataneo C., Eldib R. Thomazi R., Pereira R. S., Minossi J. G.và công sứ (2013) "Efficacy of surgical versus conservative treatment in esophageal perforation: a systematic review of case series studies". Acta Cir Bras, 28 (4), tr. 266-71.

12. Huu Vinh V., Viet Dang Quang N., Van Khoi N. (2019) "Surgical management of esophageal perforation: role of primary closure". Asian Cardiovasc Thorac Ann, 27 (3), tr. 192-198.

\section{NGHIÊN CỨU ĐĂC ĐIỂM ĐIÊNN NÃO ĐỒ NGOÀI CO'N Ở BỆNH NHÂN ĐộNG KINH TÂM THẦN VẬN ĐộNG}

\section{TÓM TẮT}

Mục tiêu: Tìm hiểu đặc điểm năng lượng, biên độ và tân số của sóng alpha, sóng theta, sóng delta trên điện não đồ nền ở bệnh nhân động kinh tâm thần vận động. Phương pháp nghiên cứu: Phân tích về chỉ sổ năng lượng, tần số và biên độ của sóng alpha sóng theta, sóng delta trên 23 bệnh nhân động kinh tâm thần vận động được điều trị tại Khoa Tâm thân, Bênh viện Quân y 103. Kết quả nghiên cứu: Năng lượng, biển độ sóng alpha là thấp nhất, tiếp đến là năng lương, biên đô sóng delta và cao nhất là năng lượng, biển độ sóng theta. Tần số của sóng alpha, sóng theta, sóng delta có sư biến đônng nhỏ. Kết luấn: Kết quả nghiên cứu này đưa ra bằng chứng về sự biến đổi sóng alpha, sóng theta, sóng delta ở bệnh nhân động kinh tâm thần vần đông. đồ.

Tư khóa: Động kinh tâm thần vận động, điện não

\footnotetext{
${ }^{1}$ Bệnh viện Quân y 103

Chịu trách nhiệm chính: Đinh Việt Hùng

Email: bshunga6@gmail.com

Ngày nhận bài: 10.9.2021

Ngày phản biện khoa học: 25.10.2021

Ngày duyệt bài: 12.11.2021
}

Đinh Việt Hùng

\section{SUMMARY \\ RESEARCH ON EEG EXTERNAL ATTACKS CHARACTERISTICS IN PATIENTS WITH PSYCHOMOTOR EPILEPSY}

Objectives: Understanding the energy, amplitude, and frequency characteristics of Alpha waves, Theta waves, Delta waves on baseline EEG in patients with psychomotor epilepsy. Methods: Analysis of energy index, frequency, and amplitude of Alpha waves, Theta waves, Delta waves on 23 patients with psychomotor epilepsy treated at the Department of Psychiatry, 103 Military Hospital. Results: The energy and amplitude of Alpha waves were the lowest, followed by the energy and amplitude of Delta waves, and the highest index was the energy and amplitude of Theta waves. The frequency of Alpha waves, Theta waves, Delta waves had a slight variation. Conclusion: The results of this study provided evidence of the Alpha, Theta, and Delta waves changes in patients with psychomotor epilepsy.

Keywords: Psychomotor epilepsy, Electroencephalogram.

I. ĐĂTT VẤN ĐỀ

Động kinh là một bệnh lý phổ biến trên thễ 